\title{
EFISIENSI PEMASARAN JAGUNG DI KELURAHAN KALAMPANGAN KECAMATAN SABANGAU KOTA PALANGKA RAYA
}

\author{
EFFICIENCY OF MAIZE MARKETING \\ IN KALAMPANGAN VILLAGE SABANGAU SUBDISRTICT \\ PALANGKA RAYA CITY
}

\author{
${ }^{1}$ Novica Sari Br Purba, ${ }^{2}$ H. Ahmad Zaki Yamani, ${ }^{3}$ Pordamantra \\ ${ }^{1}$ Alumnus Program Studi Agribisnis Fakultas Pertanian Universitas Palangka Raya \\ ${ }^{2,3}$ Staf Pengajar Program Studi Agribisnis Fakultas Pertanian Universitas Palangka Raya \\ email:ahmad.zaki@agb.upr.co.id
}

\begin{abstract}
ABSTRAK
Penelitian ini bertujuan untuk menganalisis saluran pemasaran, lembaga pemasaran, fungsi pemasaran, marjin pemasaran, biaya pemasaran, keuntungan pemasaran, share petani jagung, efisiensi pemasaran jagung pada berbagai saluran di Kelurahan Kalampangan. Hasil penelitian menunjukkan bahwa: (1) pemasaran jagung di Kelurahan Kalampangan ada dua macam saluran, dimana Saluran I melibatkan dua lembaga yaitu pedagang tingkat kelurahan dan pedagang pengecer. Selanjutnya Saluran II tidak melibatkan lembaga karena petani langsung menjual hasil panen jagungnya ke konsumen di pasar. Fungsi-fungsi pemasaran jagung yang dilakukan yaitu: fungsi penjualan, fungsi pembelian, fungsi penyimpanan, fungsi pengangkutan dan fungsi fasilitas. (2) Pada Saluran Pemasaran I, total marjin pemasaran jagung di Kelurahan Kalampangan sebesar Rp.3.860 per kg, besar total biaya pemasaran jagung sebesar Rp. 310 per kg, total keuntungan pemasaran jagung sebesar Rp. 3.550 per kg dan share petani sebesar 58,04\%. Sedangkan pada Saluran Pemasaran II, total marjin pemasaran jagung yaitu sebesar Rp.1.850 per kg, besar total biaya pemasaran jagung yaitu sebesar Rp.310 per kg, total keuntungan pemasaran jagung sebesar Rp.1.850 per kg dan share petani sebesar 71,20\%. (3) Nilai efisiensi pemasaran pada Saluran Pemasaran I sebesar 41,96\% lebih tinggi dibandingkan dengan nilai efisiensi Saluran Pemasaran II adalah 28,80\%, sehingga Saluran Pemasaran II dianggap lebih efisien.
\end{abstract}

Kata kunci: Efisiensi, jagung, marjin pemasaran, saluran pemasaran, share petani

\section{ABSTRACT}

The aim of this research is to analyze marketing channel, marketing institution, marketing function, marketing margin, marketing cost, marketing profit, corn farmer's share, marketing efficiency of maize in various channel in Kalampangan village. The results showed that: (1) marketing of corn in Kalampangan village there are two kinds of channels, where channel I involves four institutions namely: farmers, merchants village, retailers, and consumers. While channel II involves two institutions only, namely, farmers as traders and consumers. Maize's marketing functions are: sales function, purchasing function, storage function, transport function and facility function. (2) From calcution result at Marketing Channel I, total marketing margin of maize in Kalampangan Villge is Rp. 3.860,-/kg, total cost of corn marketing is Rp. 310,-/kg, total profit of corn marketing is Rp. 3.550,-/kg and the result 
obtained by corn farmer are 58,04\%. From calculating result at Marketing Channel II, total margin of maize in Kalampangan Village is Rp. 2.160,- $/ \mathrm{kg}$, total cost of corn marketing is Rp. $310,-/ \mathrm{kg}$, total profit of corn marketing is Rp. 1.850,-/kg and the result obtained by corn farmer are 71,20\%. (3) marketing efficiency at Marketing Channel I equal to 41.96\%, and on Marketing Channel II is 28,80\%. Marketing efficiency value in Channel I is lower than marketing efficiency II, it is considered more efficient marketing Channel II.

Keywords: Corn, efficiency, farmer share, marketing line, marketing margin

\section{PENDAHULUAN}

Jagung sebagai tanaman pangan di Indonesia, menduduki urutan kedua setelah padi dalam hal luas panennya, luas panen padi pada tahun 2014 sebesar 13.797.307 Ha, sedangkan luas panen jagung sebesar 3.837.019 Ha (Badan Pusat Statistik, 2014). Kebutuhan jagung di Indonesia saat ini cukup besar, yaitu lebih dari 10 juta ton pipilan kering per tahun. Adapun konsumsi jagung terbesar untuk pangan dan industri pakan ternak. Hal ini dikarenakan 51\% bahan baku pakan ternak adalah jagung (Haryanto,2013).

Permintaan jagung terus meningkat seiring meningkanya jumlah populasi dan industri. Data statistik menunjukkan bahwa luas panen dan produksi jagung di Kalimantan Tengah selama periode19962013 sangat fluktuatif, tetapi memiliki kecendrungan meningkat. Kalimantan Tengah ideal untuk potensi pertanaman jagung karena ketersediaan potensi lahan suboptimal yang luas.Kalimantan Tengah sebagai salah satu provinsi dengan agrosistem yang beragam mempunyai potensi untuk pengembangan jagung (Badan Pusat Statistik Provinsi Kalimantan Tengah, 2014).

Pemasaran merupakan proses yang harus dilalui petani sebagai produsen untuk menyalurkan produknya hingga sampai ke tangan konsumen. Seringkali dijumpai adanya rantai pemasaran yang panjang dengan banyak pelaku pemasaran menjadi besar yang akhirnya akan mempengaruhi tingkat harga. Pemasaran hasil panen jagung merupakan salah satu kendala pengembangan jagung di Kelurahan
Kalampangan.Pemasaran jagung yang melibatkan lembaga pemasaran pada akhirnya mempengaruhi pembentukan harga jual jagung. Penelitian ini bertujuan untuk menganalisis saluran pemasaran, lembaga pemasaran yang terlibat dalam fungsi pemasaran, marjin, biaya dan keuntungan pemasaran, share petani jagung, dan menganalisis efisiensi pemasaran jagung pada berbagai saluran pemasaran di Kelurahan Kalampangan.

\section{METODE PENELITIAN}

Penelitian ini berlokasi di Kelurahan Kalampangan, Kecamatan Sabangau, Kota Palangka Raya. Alasan Pemilihan lokasi adalah: (1) Lokasi ini merupakan sentra produksi; (2) di daerah ini terdapat kesenjangan marjin di petani dan pedagang, dimana pedagang lebih besar memperoleh keuntungan dibanding petani.

Penentuan sampel dilakukan dengan menggunakan metode acak stratifikasi (stratified random sampling), dimana sebuah sampel diambil berdasarkan stratifikasi/tingkatan. Populasi dapat distratifikasikan dalam lapisan lapisan dengan menggunakan saluran pemasaran yang digunakan petani sebagai kriteria.

Di Kelurahan Kalampangan, ada sebanyak 477 KK yang mengusahakan usahatani campuran. Dari 477 KK petani terdiri dari dua kelompok yang menggunakan saluran yang berbeda dalam pemasaran hasil jagungnya. Kelompok Pertama adalah kelompok yang menggunakan Saluran Pemasaran I yaitu petani yang menjual hasil panen jagungnya 
ke pedagang tingkat kelurahan ada sebanyak 366 KK dan Saluran Pemasaran II yaitu petani yang langsung menjual hasil panennya ke konsumen ada sebanyak 111 KK. Dari jumlah populasi berdasarkan strata yang ada di Kelurahan Kalampangan tersebut dipilih sampel sebanyak $30 \mathrm{KK}$ yang terdiri dari $23 \mathrm{KK}$ yang menggunakan Saluran Pemasaran I dan $7 \mathrm{KK}$ yang menggunakan Saluran Pemasaran II, sedangkan pedagang sampel yang terlibat ditentukan dengan metode bola salju.

Data yang digunakan dalam penelitian ini adalah data primer dan data sekunder. Data primer diambil melalui wawancara langsung dengan petani jagung dan pedagang yang terpilih menjadi responden, menggunakan kuisioner atau daftar pertanyaan serta melakukan observasi ke lokasi penelitian, tempat usaha dan pasar. Data primer tersebut meliputi identitas petani, luas lahan jagung, sistem pemasaran, fungsi pemasaran yang dilakukan, harga jagung dan jumlah saluran pemasaran yang terlibat dalam pemasaran jagung. Data primer yang lain yang dikumpulkan adalah identitas pedagang, biaya pemasaran yang di tanggung oleh pedagang, fungsi pemasaran yang dilakukan (transportasi) harga beli dan harga jual pada masing-masing konsumen dan beberapa keterangan lain yang menyangkut kendala-kendala yang dihadapi dalam aktivitas jual beli.

Data sekunder diperoleh dari lembaga atau instansi terkait seperti Badan Pusat Statistik Provinsi Kalimantan Tengah, Dinas Perdagangan dan Perindustrian Kalimantan Tengah dan hasil observasi. Data sekunder tersebut meliputi keadaan umum lokasi penelitian, perkembangan luas panen dan produksi jagung menurut Kecamatan di Kota Palangka Raya dan data data lain yang berhubungan dengan penelitian ini.

Data yang telah dikumpulkan selanjutnya diedit dan diolah secara manual dalam bentuk tabel (tabulasi) sederhana disesuaikan dengan tujuan penelitian. Pengolahan data kuantitatif dilakukan dengan bantuan alat hitung atau komputer dan perhitungan disesuaikan dengan alat analisis yang digunakan. Data kuantitatif diuraikan secara deskriptif artinya data tersebut akan diuraikan dan dijelaskan dengan kalimat guna memberikan gambaran yang jelas tentang data tersebut.

Untuk menjawab tujuan penelitian, analisis data yang akan digunakan adalah sebagai berikut:

1. Untuk menjawab tujuan pertama, yaitu menganalisis saluran pemasaran jagung dan lembaga-lembaga serta fungsifungsi pemasaran yang terlibat dilakukan secara deskriptif, yaitu menguraikan hasil pengamatan di lapangan dalam bentuk kalimat untuk memberikan gambaran yang jelas tentang berbagai saluran pemasaran jagung dan lembaga-lembaga yang terlibat.

2. Untuk menjawab tujuan kedua penelitian ini yaitu menganalisis besarnya margin pemasaran, biaya pemasaran, keuntungan pemasaran jagung dan farmer's share dilakukan perhitungan secara metematis dari hubungan marjin pemasaran dan biaya pemasaran yang dinyatakan sebagai berikut:

a. Untuk mengetahui marjin pemasaran yang diterima oleh masing-masing lembaga, dapat ditulis dengan persamaan sebagai berikut (Hutabarat, 2001):

Keterangan:

$$
\mathrm{Mj}=\mathrm{Hk}-\mathrm{Hp}
$$

$\mathrm{Mji}=$ MarjinPemasaran $(\mathrm{Rp} / \mathrm{kg})$

$\mathrm{Hki}=$ Harga di tingkat konsumen (Rp/kg)

Hpi = Harga di tingkat produsen (Rp/kg)

b. Biaya pemasaran adalah keseluruhan biaya yang dikeluarkan dalam proses 
pergerakan barang dari tangan produsen ke konsumen, dapat dihitung dengan persamaan sebagai berikut:

Keterangan:

$$
\mathrm{Bp}=\mathrm{Mj}-\mathrm{n}
$$

$$
\begin{aligned}
\mathrm{Bp}= & \text { Biaya pemasaran }(\mathrm{Rp} / \mathrm{kg}) \\
\mathrm{Mj}= & \text { Marjin pemasaran }(\mathrm{Rp} / \mathrm{kg}) \\
\mathrm{N}= & \text { Keuntungan pemasaran } \\
& (\mathrm{Rp} / \mathrm{kg})
\end{aligned}
$$

c. Besarnya keuntungan lembagalembaga pemasaran tingkat $i$ dapat dihitung dengan persamaan sebagai berikut:

Keterangan:

$$
\mathrm{n}=\mathrm{Mj}-\mathrm{Bp}
$$

$$
\begin{aligned}
\mathrm{N} & =\begin{array}{l}
\text { Keuntungan pemasaran } \\
(\mathrm{Rp} / \mathrm{kg})
\end{array} \\
\mathrm{Mj} & =\text { Marjin pemasaran }(\mathrm{Rp} / \mathrm{kg}) \\
\mathrm{Bp} & =\text { Biaya pemasaran }(\mathrm{Rp} / \mathrm{kg})
\end{aligned}
$$

d. Untuk menghitung bagian yang diterima petanisecara matematis dapat digunakan rumus sebagai berikut:

$$
\mathrm{Fs}=\frac{\mathrm{Pt}}{\mathrm{Pr}} \times 100 \%
$$

Keterangan:

Fs $=$ Farmer's share

$\begin{array}{ll} & \text { Pedagang } \\ \text { SP I } & \text { Tingkat } \\ & \text { Kelurahan }\end{array}$

$\mathrm{Pf}=$ Harga ditingkat petani
$\mathrm{Pr}=$ Harga ditingkat konsumen

3. Untuk menjawab tujuan ketiga dalam penelitian ini yaitu mengenai efisiensi pemasaran jagung dihitung dengan menggunakan persamaan sebagai berikut:

$$
\mathrm{EP}=\frac{\mathrm{Mjt}}{\mathrm{Hta}} \mathrm{x} 100 \%
$$

$$
\begin{aligned}
& \mathrm{EP}=\text { Efisiensi Pemasaran } \\
& \mathrm{Mjt}=\text { Marjin Total Pemasaran } \\
& \mathrm{Hta}=\text { Harga ditingkat konsumen }
\end{aligned}
$$

\section{HASIL DAN PEMBAHASAN}

\section{Saluran dan Lembaga Pemasaran}

Berdasarkan hasil pengamatan selama melakukan penelitian, di Kelurahan Kalampangan terdapat dua macam saluran pemasaran jagung, dimana salah satunya melibatkan dua lembaga, sedangkan yang satunya langsung ke konsumen akhir. Sehingga kedua saluran pemasaran tersebut tidak memiliki saluran pemasaran yang panjangnya sama. Untuk lebih jelasnya, kedua saluran tersebut dapat dilihat pada Gambar 1 berikut.

\section{Pedagang \\ Pengecer}

\section{SP II Petani}

Konsumen

Gambar 1. Saluran Pemasaran Jagung di Kelurahan Kalampangan Sumber: Data primer yang diolah, 2017.

\begin{abstract}
Berdasarkan Gambar 1, Saluran Pemasaran jagung di Kelurahan Kalampangan terdapat $76,66 \%$ (23 KK petani) yang melakukan sistem pemasaran pada saluran I dan 23,33\% (7 KK petani) yang melakukan sistem pemasaran pada saluran pemasaran II. Adapun keadaan saluran pemasaran serta keterlibatan
\end{abstract}

lembaga-lembaga pemasaran seperti Gambar 1, dijelaskan sebagai berikut:

a. Saluran Pemasaran I

Pada Saluran Pemasaran I terdapat dua lembaga pemasaran yang terlibat yaitu pedagang tingkat kelurahan dan pedagang pengecer. Petani menjual jagung tersebut dalam bentuk borongan kepada pedagang tingkat kelurahan. Biaya penjualan yang 
digunakan petani untuk menjual jagungnya tidak ada karena sudah termasuk kedalam harga jual.

Pada Kelurahan Kalampangan, pedagang tingkat kelurahan membeli jagung dengan langsung mendatangi petani jagung, sehingga pedagang tingkat kelurahan yang ada di Kelurahan Kalampangan ini mengeluarkan biaya pembelian yang merupakan biaya transportasi dan tanpa adanya pengolahan lebih lanjut. Selanjutnya pedagang tingkat kelurahan menjual jagung kepada pedagang pengecer di Pasar Kota Palangka Raya.

b. Saluran Pemasaran II

Pada Saluran Pemasaran II ini melibatkan satu lembaga pemasaran saja yaitu petani jagung (produsen). Petani menjual langsung jagung hasil panennya sendiri ke pasar di Kota Palangka Raya di sini petani bertindak sebagai produsen. Pada Saluran Pemasaran II, petani jagung yang melakukan penjualan kepada konsumen terlebih dahulu menanggung biaya penjualan yaitu biaya pembelian karung, plastik dan biaya transportasi serta waktu untuk menjual jagung tersebut ke pasar di Kota Palangka Raya.

\section{Fungsi-fungsi Pemasaran}

Fungsi lembaga pemasaran bertujuan mengusahakan agar pembeli memperoleh barang yang diinginkan pada tempat, waktu, dan harga yang tepat. Fungsi lembaga pemasaran jagung yang terjadi di Kota Palangka Raya dilakukan oleh lembaga-lembaga pemasaran yang terlibat langsung dalam pemasaran tersebut. Dalam kegiatan pemasaran jagung di loksi penelitian lembaga-lembaga pemasaran yang melakukan fungsi-fungsi pemasaran yaitu:

a. Pedagang Tingkat Kelurahan

Pedagang tingkat Kelurahan melakukan fungsi pertukaran dan fungsi fisik. Fungsi pertukaran merupakan aktivitas pemilihan yang berupa pengalihan hak kepemilikan. Fungsi pertukaran ada dua yaitu, penjualan dan pembelian. Dalam hal ini pihak produsen melakukan fungsi penjualan karena pihak tersebut menjual jagung ke pedagang besar. Fungsi pembeliaan terjadi karena pedagang membeli jagung tersebut ke produsen (petani) dan fungsi penjualan, pedagang besar menjual kembali ke pedagang pengecer.

Pedagang besar melakukan fungsi
fisik dengan melakukan fungsi pengangkutan dan penyimpanan, karena pedagang besar mengangkut jagung dari petani sampai pada tempatnya dan proses pengangkutan tersebut dilakukan melalui jalan darat dan transportasi yang dilakukan dengan kendaraan milik sendiri. Selain fungsi pengangkutan, pedagang besar juga melakukan fungsi penyimpanan, karena sesudah pesanan jagung tersebut datang maka akan disimpan di gudang agar terhindar dari cuaca buruk yang akan merusak mutu jagung.

b. Pedagang Pengecer

Pedagang pengecer melakukan fungsi fasilitas, dimana dalam fungsiyang berguna mengangkut jagung yang sudah dibeli dari pedagang besar. Fungsi ini dilakukan untuk memperlancar kegiatan pemasaran. Pedagang pengecer juga menggunakan fungsi informasi pasar untuk mengumpulkan fakta harga-harga barang yang ada di pasar Kota Palangka Raya.

Dalam pemasaran jagung, peagang menggunakan sistem tertentu untuk memperoleh.

\section{Marjin Pemasaran}

Analisis marjin pemasaran dan bagian harga merupakan salah satu cara yang digunakan untuk mengetahui efisiensi pemasaran. Untuk mengetahui besar marjin pemasaran dilakukan perhitungan biaya yang dikeluarkan. Besarnya keuntungan yang lebih tinggi. Harga yang diterima petani sampai ke tangan konsumen untuk 
masing-masing saluran tidak sama. Untuk

lebih jelasnya dapat dilihat pada Tabel 1

Tabel 1. Harga Jual, Keuntungan dan Marjin Pemasaran Jagung di Kelurahan Kalampangan, Kecamatan Sabangau, Kota Palangka Raya

\begin{tabular}{|c|c|c|c|c|c|}
\hline \multirow[b]{2}{*}{ No. } & \multirow[b]{2}{*}{ Uraian } & \multicolumn{2}{|c|}{ Saluran Pemasaran I } & \multicolumn{2}{|c|}{ Saluran Pemasaran II } \\
\hline & & $\begin{array}{c}\text { Harga } \\
\text { (Rp) }\end{array}$ & $\begin{array}{c}\text { Share } \\
(\%)\end{array}$ & $\begin{array}{c}\text { Harga } \\
\text { (Rp) }\end{array}$ & $\begin{array}{c}\text { Share } \\
(\%)\end{array}$ \\
\hline \multirow[t]{3}{*}{1.} & Petani: & & & & \\
\hline & Harga Jual & 5.340 & 58,04 & 5.640 & 71,20 \\
\hline & Biaya Pemasaran & & & 310 & 4.13 \\
\hline \multirow[t]{6}{*}{2.} & Pedagang Tingkat Kelurahan: & & & & \\
\hline & Harga Beli & 5.340 & 58,04 & & \\
\hline & Harga Jual & 7.500 & 81,52 & & \\
\hline & Marjin Pemasaran & 2.160 & 23,48 & & \\
\hline & Biaya Pemasaran & 275 & 2,99 & & \\
\hline & Keuntungan Pemasaran & 1.885 & 20,49 & & \\
\hline \multirow[t]{6}{*}{3.} & Pedagang Pengecer: & & & & \\
\hline & Harga Beli & 7.500 & 81,92 & & \\
\hline & Harga Jual & 9.200 & 100,00 & & \\
\hline & Marjin Pemasaran & 1.700 & 18,48 & & \\
\hline & Biaya Pemasaran & 35 & 0,38 & & \\
\hline & Keuntungan Pemasaran & 1.665 & 18,98 & & \\
\hline \multirow[t]{2}{*}{4.} & Konsumen Akhir: & & & & \\
\hline & Harga Beli & 9.200 & 100,00 & 7.500 & 100.00 \\
\hline 5. & Total Marjin Pemasaran & 3.860 & 41,95 & 2.160 & 28,80 \\
\hline 6. & Total Biaya Pemasaran & 310 & 3,37 & 310 & 4,13 \\
\hline 7. & Total Keuntungan Pemasaran & 3.550 & 38.58 & 1.850 & 24,67 \\
\hline
\end{tabular}

Sumber: Data primer yang diolah, 2017.

Marjin pemasaran yang diolah pada penelitian ini berasal dari selisih antara harga yang diterima produsen dan harga yang dibayar oleh konsumen. Untuk lebih lengkapnya marjin pemasaran dalam penelitian ini dapat dilihat pada Tabel 2.

Tabel 2. Marjin Pemasaran Jagung Pada Berbagai saluran di Kelurahan Kalampangan

\begin{tabular}{ccccc}
\hline $\begin{array}{c}\text { Saluran } \\
\text { Pemasaran }\end{array}$ & $\begin{array}{c}\text { Petani } \\
(\mathrm{Rp})\end{array}$ & $\begin{array}{c}\text { Pedagang Tingkat } \\
\text { Kelurahan } \\
(\mathrm{Rp})\end{array}$ & $\begin{array}{c}\text { Pedagang } \\
\text { Pengecer } \\
(\mathrm{Rp})\end{array}$ & $\begin{array}{c}\text { Jumlah } \\
(\mathrm{Rp})\end{array}$ \\
\hline I & - & 2.160 & 1.700 & 3.860 \\
\hline II & 2.160 & - & - & 2.160 \\
\hline
\end{tabular}

Sumber: Data primer yang diolah, 2017.

Pada Tabel 2, terlihat bahwa total marjin pemasaran pada saluran I yaitu sebesar Rp. 3.860 per $\mathrm{kg}$ yang terdiri dari pedagang tingkat kelurahan sebesar Rp. 2.160 per $\mathrm{kg}$ dan pedagang pengecer sebesar Rp. 1.700 per kg. Sedangkan pada Saluran Pemasaran II, total marjin pemasarannya adalah sebesar Rp. 2.160 per kg. 


\section{Biaya Pemasaran}

Biaya Pemasaran merupakan keseluruhan yang dikeluarkan dalam proses pergerakan barang (jagung) dari produsen/petani ke konsumen akhir yang dinyatakan dengan $\mathrm{Rp}$ per $\mathrm{kg}$ jagung. Sedangkan keuntungan selisih antara marjin pemasaran dengan biaya pemasaran yang dinyatakan dengan Rp per kg jagung.

Pada Saluran Pemasaran I, biaya pembelian maupun biaya pemasaran ditanggung oleh pedagang tingkat kelurahan. Biaya yang ditanggung antara lain adalah biaya transportasi sebesar Rp. 250,- per kg, dan karung sebesar Rp. 25,- per kg. Sedangkan pada Saluran Pemasaran II, biaya yang dikeluarkan hanya biaya pemasaran yaitu biaya retribusi sewa tempat atau lokasi sebesar Rp. 10 per kg, plastik sebesar Rp. 25 per kg, transportasi Rp. 250 per kg dan biaya karung sebesar Rp. 25 per kg. Pada Saluran Pemasaran I, pedagang tingkat maupun pedagang pengecer menanggung biaya pembelian, hal ini disebabkan karena pedagang tersebut membeli jagung langsung ke petani, selanjutnya pedagang tingkat kelurahan menjualnya kembali ke pedagang pengecer sehingga memerlukan biaya pembelian yaitu biaya transportasi (biaya pemasaran). Pada pedagang tingkat kelurahan biaya pemasaran ini merupakan biaya transportasi yaitu Rp. 250 per kg, dan karung sebesar Rp. 25 per kg. Sedangkan pada pedagang pengecer biaya yang ditanggung adalah biaya retribusi yaitu Rp. 10 per $\mathrm{kg}$, dan biaya pembelian plastik sebesar Rp. 25 per $\mathrm{kg}$. Sedangkan pada Saluran Pemasaran II juga menanggung biaya pemasaran, yaitu biaya penjualan oleh petani kepada konsumen yaitu, retribusi sebesar Rp. 10 per kg, plastik sebesar Rp. 25 per kg dan transportasi sebesar Rp. 250 per kg. Total biaya pemasarannya adalah Rp. 310 per kg. Data mengenai total biaya dapat dilihat pada Tabel 1. Biaya total pada saluran pemasaran I adalah Rp. 310 per $\mathrm{kg}$ dari harga jual tingkat akhir di tingkat konsumen. Data mengenai biaya total pada Saluran Pemasaran I dapat dilihat pada Tabel 1.

\section{Keuntungan Pemasaran}

Besarnya keuntungan pemasaran jagung yang diterima oleh para petani, pedagang tingkat kelurahan, dan pedagang pengecer tidaklah sama. Pada saluran pemasaran I, keuntungan pemasaran yang diterima pedagang tingkat kelurahan dan pedagang pengecer lebih kecil daripada keuntungan yang diperoleh pada saluran pemasaran II. Pada saluran pemasaran I keuntungan pemasaran yang diperoleh petani sebesar harga jualnya yaitu Rp. 5.340. Keuntungan yang diperoleh pedagang tingkat kelurahan adalah sebesar Rp. 1.885 per $\mathrm{kg}$, dan pedagang pengecer sebesar Rp. 1.665 per $\mathrm{kg}$, sedangkan bagian hasil yang terbesar diterima oleh petani terdapat pada Saluran Pemasaran II sebesar 71,20\%, karena petani langsung bertindak sebagai pengecer, sedangkan pada saluran pemasaran I bagian hasil yang diterima adalah sebesar 58,04\%.

\section{Efisiensi Pemasaran}

Untuk mengukur tingkat efisiensi pemasaran dari tingkat petani jagung sampai tingkat keuntungan pemasaran pada Saluran pemasaran II, sebesar Rp. 1.850 per kg. Untuk lebih jelasnya dapat dilihat pada Tabel 1.

\section{Share Petani}

F armer's share merupakan perbandingan harga yang diterima petani dengan harga yang dibayar oleh konsumen akhir dan dinyatakan dalam persentase. Farmer's share memiliki hubungan negatif dengan marjin pemasaran, dimana semakin tinggi marjin pemasaran maka bagian yang akan diperoleh petani semakin rendah. Bagian hasil pada berbagai saluran dilihat pada Tabel 3 berikut. 
Tabel 3. Farmer's Share pada Berbagai Saluran Pemasaran Jagung di Kelurahan Kalampangan

\begin{tabular}{cccc}
\hline Saluran Pemasaran & $\begin{array}{c}\text { Harga ditingkat } \\
\text { Petani } \\
(\mathrm{Rp} / \mathrm{Kg})\end{array}$ & $\begin{array}{c}\text { Harga ditingkat } \\
\text { Konsumen } \\
(\mathrm{Rp} / \mathrm{Kg})\end{array}$ & $\begin{array}{c}\text { F armer's Share } \\
(\%)\end{array}$ \\
\hline I & 5.340 & 9.200 & 58,04 \\
\hline II & 5.340 & 7.500 & 71,20 \\
\hline
\end{tabular}

Sumber: Data primer yang diolah, 2017.

Bagian hasil yang terbesar diterima oleh petani terdapat pada Saluran Pemasaran II sebesar 71,20\%, karena petani langsung bertindak sebagai pengecer, sedangkan pada Saluran I, bagian hasil yang diterima sebesar $58,04 \%$.

\section{Efisiensi Pemasaran}

Untuk mengukur tingkat efisiensi pemasaran dari tingkat petani jagung sampai tingkat konsumen akhir dapat

Tabel 4. Efisiensi Pemasaran Jagung di Kelurahan Kalampangan, Kecamatan Sabangau, Kota Palangka Raya

\begin{tabular}{|c|c|c|c|}
\hline No. & Uraian & $\begin{array}{l}\text { Saluran Pemasaran } \\
\text { I }\end{array}$ & $\begin{array}{c}\text { Saluran Pemasaran } \\
\text { II }\end{array}$ \\
\hline 1 & Harga di tingkat petani $(\mathrm{Rp} / \mathrm{kg})$ & 5.340 & 5.340 \\
\hline 2 & Harga di tingkat konsumen akhir ( $\mathrm{Rp} / \mathrm{kg})$ & 9.200 & 2.160 \\
\hline 3 & Marjin pemasaran $(\mathrm{Rp} / \mathrm{Kg})$ & 3.860 & 2.160 \\
\hline 4 & Efisensi pemasaran & $41,96 \%$ & $28,80 \%$ \\
\hline
\end{tabular}

Sumber: Data primer yang diolah, 2017.

Dari Tabel 4 dapat dilihat tingkat efisiensi pemasaran pada Saluran Pemasaran I adalah sebesar $41,96 \%$ dan pada Saluran Pemasaran II adalah sebesar $28,80 \%$. Nilai efisiensi pemasaran pada saluran II lebih rendah dari nilai efisiensi pemasaran I, maka dianggap saluran pemasaran II lebih efisien.

\section{KESIMPULAN DAN SARAN}

\section{Kesimpulan}

Berdasarkan hasil dan pembahasan, maka dapat disimpulkan, sebagai berikut:

1. Sistem pemasaran jagung di Kelurahan Kalampangan terdapat dua saluran pemasaran, Saluran Pemasaran I melibatkan petani jagung, pedagang menggunakan marjin pemasaran. Dari hasil penelitian perbedaan harga di tingkat petani jagung dengan harga di tingkat konsumen akhir atau marjin pemasaran pada saluran pemasaran jagung pada lokasi penelitian dapat dilihat pada Tabel 4 . 
sebesar Rp. 310 per $\mathrm{kg}$, total keuntungan pemasaran jagung yaitu sebesar Rp. 3.550 per kg dan share petani sebesar 58,04\%. Sedangkan pada Saluran Pemasaran II, total marjin pemasaran jagung sebesar Rp.2.160 per $\mathrm{kg}$, besar total biaya pemasaran jagung sebesar Rp. 310 per $\mathrm{kg}$, total keuntungan pemasaran jagung sebesar Rp. 1.850 per $\mathrm{kg}$ dan share petani sebesar $71,20 \%$.

3. Nilai efisiensi pemasaran pada Saluran Pemasaran I yaitu sebesar $41,96 \%$ lebih tinggi dibandingkan dengan nilai efisiensi Saluran Pemasaran II adalah $28,80 \%$, sehingga saluran pemasaran II dianggap lebih efisien.

\section{Saran}

Berdasarkan beberapa kesimpulan di atas maka disarankan, sebagai berikut:

1. Petani diharapkan sudah dapat memilih atau menerapkan saluran mana yang akan digunakan dalam pemasaran hasil jagungnya untuk mendapatkan keuntungan yang lebih tinggi dengan meminimalkan biaya pemasaran.

2. Pemerintah di Kelurahan Kalampangan diharapkan memberikan kebijakan atau meransang munculnya organisasiorganisasi ditingkat petani yang dapat memudahkan petani memasarkan hasil pertaniannya.

3. Peneliti yang ingin meneliti lebih lanjut masalah pemasaran jagung di Kota Palangka Raya disarankan untuk lebih dalam lagi mengulas tentang faktorfaktor yang mempengaruhi produksi, harga jagung dan struktur pasar jagung di Kota Palangka Raya.

\section{DAFTAR PUSTAKA}

AAK. (1993). Seri Budidaya Jagung. Yogyakarta: Penerbit Kanisius.

Badan Pusat Statistik Kota Palangka Raya. (2014). Palangka Raya Dalam Angka. 2014. Palangka Raya:
Badan Pusat Statistik Kota Palangka Raya.

Badan Pusat Statistik. (2014). Luas Panen Tanaman Jagung di Indonesia Tahun 2012. Jakarta: Badan Pusat Statistik.

Badan Pengkajian dan Teknologi Pertanian Kalimantan Tengah. (2015). Perkembangan Pertanian di Kelurahan Kalampangan Tahun 2015. Palangka Raya: BPTP Kalimantan Tengah.

Dinas Pertanian dan Peternakan Kota Palangka Raya. (2017). Perkembangan Harga Rata-Rata Jagung Tahun 2014-2016 di Kota Palangka Raya. Palangka Raya.

Firdaus, Muhammad. (2008). Ekonomi Suatu Pendekatan Aplikatif. Jakarta: Bumi Aksara.

Haryanto, Budiman. (2013). Sukses Bertanam Jagung. Yogyakarta: Pustaka Baru Press.

Hutabarat, M. (2001). Analisis Pemasaran Karet Rakyat di Kecamatan Kahayan Hilir Kabupaten Kapuas. Skripsi. Jurusan Sosial Ekonomi Pertanian, Fakultas Pertanian, Universitas Palangka Raya. Palangka Raya.

Kotler, Philip. (1980). Manajemen dan Aplikasinya. Jakarta: PT. Raja Grafindo Persada.

Masyofie. (1994). Pengantar Ekonomi Pertanian. Edisi Revisi. Jakarta: LP3ES.

Mubyanto. (1989). Pengantar Ekonomi Pertanian. Jakarta: Penebar Swadaya.

Prayitno, A. (2012). Analisis Efisiensi Produksi, Pendapatan Usahatani dan Efisiensi Pemasaran Cabai Merah (Capsium Annum) Hibrida di Kabupaten Pringsewu. http://digilib.unila.ac.id/6736/ Diakses pada tanggal 19 Mei 2017. 
Purwono dan Heni. (2013). Budidaya 8 Jenis Tanaman Pangan Unggul. Jakarta: Penebar Swadaya.

Purwono dan Rudi. (2005). Bertanam Jagung Unggul. Jakarta: Penebar Swadaya.

Santoso, Teguh Iman. (2014). Efisiensi Pemasaran Beberapa Komoditas Sayuran Utama di Kabupaten Indramayu.

http://agribisnis.fp.uns.ac.id/wpcontent/uploads/2014/01/Efisie nsiPemasaran.pdf Diakses pada tanggal 16 April 2017.

Soekartawi, (2002). Prinsip Dasar Manajemen Pemasaran Hasil-Hasil Pertanian Teori dan Aplikasinya. Jakarta: PT Raja Grafindo Persada.

Sumaatmadja, Nursid. (1989). Studi Geografi: Suatu Pendekatan dan Analisis Keruangan. Jakarta: Rajawali. Jakarta.

Vustany, Rovi Octaviono. (2000). Analisis Efisiensi Pemasaran Jagung di Kelurahan Kalampangan Kecamatan Pahandut Kota Palangka Raya (Skripsi). Jurusan Sosial Ekonomi Pertanian. Universitas Palangka Raya.

Wulandari, Y. (2003). Analisis Pemasaran Beras Bengawan di Kecamatan Pahandut Kota Palangka Raya. Skripsi. Jurusan Sosial Ekonomi Pertanian, Fakultas Pertanian, Universitas Palangka Raya. Palangka Raya 